\title{
Transient tachypnea of the newborn: are there bedside clues for predicting the need of ventilation support?
}

\author{
Dilek Kahvecioğlu, Ufuk Çakır, Duran Yıldız, Serdar Alan, Ömer Erdeve, Begüm Atasay, \\ Saadet Arsan \\ Division of Neonatology, Department of Pediatrics, Ankara University Faculty of Medicine, Ankara, Turkey. \\ E-mail: dileksaracoglu@yahoo.com \\ Received: 27th November 2014, Revised: 12th December 2014, Accepted: 27th October 2016
}

\begin{abstract}
SUMMARY: Kahvecioğlu D, Çakır U, Yıldız D, Alan S, Erdeve Ö, Atasay B, Arsan S. Transient tachypnea of the newborn: Are there bedside clues for predicting the need of ventilation support? Turk J Pediatr 2016; 58: 400-405.

Decision making to transfer a late preterm or term neonate with the diagnosis of transient tachypnea of the newborn (TTN) to an intensive care unit for respiratory support is a challenge for caregivers in level one and two NICUs. The aim of this study was to identify "practical bedside clinical clues" that may help to predict the severity of disease and need for respiratory support in patients with the diagnosis of TTN. Newborns having the diagnosis of TTN were classified into two groups according to the intensity of the respiratory support. Infants receiving only supplemental oxygen and infants requiring nasal continuous positive airway pressure or mechanical ventilation constituted group 1 (mild) and group 2 (severe), respectively. Demographic, clinical and laboratory characteristics were compared between the two groups. Patients in group 2 had lower gestational age, higher Silverman and Richardson scores, longer mean duration of oxygen support and hospitalization. A positive correlation was found between subcostal and xiphoid retractions, asynchrony in chest-abdomen movements, arterial $\mathrm{pH}<7.30$, ratio of $\mathrm{PaO}_{2} / \%$ inspired $\mathrm{O}_{2}<1.2$ and need of respiratory support $(\mathrm{p}<0.05)$. We suggest that simple scores can help physicians to get a good sense of a given baby's likelihood of deterioration.
\end{abstract}

Key words: transient tachypnea of the newborn, silverman score, richardson score.

Transient tachypnea of the newborn (TTN) is a common cause of respiratory morbidity in late preterm and term infants ${ }^{1-3}$. Delayed resorption of lung fluid is the main pathophysiological factor $^{4-6}$. The factors associated with TTN are low gestational age, male gender, low birth weight, cesarean section (CS), low APGAR scores, maternal asthma, maternal sedation and perinatal asphyxia ${ }^{1,3,5,7-10}$. TTN is generally a benign disease and treated with a brief course of oxygen. However, some of the cases need invasive or non-invasive respiratory support $6,7,11,12$.

Decision making to transfer a late preterm or term neonate with the diagnosis of TTN to a neonatal intensive care unit (NICU) for respiratory support is a challenge for caregivers in level one and two NICUs. Although TTN is usually a benign and self-limited disease, associated hypoxemia, respiratory failure and pulmonary air leak syndromes may increase the risk of morbidity ${ }^{6}$. The aim of this study was to identify "practical bedside clinical clues" from physical examination and blood gas parameters that may help to predict the severity of disease and need for invasive and non-invasive respiratory support in patients with the diagnosis of TTN.

\section{Material and Methods}

\section{Data Collection}

Prospective data were collected from patients who were delivered and admitted to the NICU at Ankara University Hospital, Ankara, Turkey between January 2012 and January 2013.

Demographic characteristics; gestational age, 
birth weight, gender, type of birth, APGAR score and clinical characteristics; initial respiratory rate, peak respiratory rate within 24 and 48 hours, presence of subcostal and xiphoid retractions, asynchrony in chestabdomen movements on physical examination, the worst arterial $\mathrm{pH}$ and ratio of arterial $\mathrm{PaO} 2$ to percent inspired $\mathrm{O}_{2}$ within 24 hours of admission and duration of non-invasive or invasive respiratory support and duration of hospitalization were all recorded. Richardson (gestational age, the worst $\mathrm{pH}$, the worst $\mathrm{PaO}_{2} / \mathrm{FiO}_{2}$ ratio, lowest blood pressure) and Silverman (chest movement, intercostal and xiphoid retractions, nasal flaring and grunting) scores were calculated to evaluate the severity of respiratory distress ${ }^{13,14}$.

\section{Study Population}

Infants who were older than $34^{\text {th }}$ week of gestation with any respiratory symptoms (tachypnea, grunting, retractions, cyanosis) persisting for more than six hours after birth were evaluated for the differential diagnosis of TTN.

The clinical diagnosis of TTN was based on the following criteria ${ }^{6}$ :

1. Respiratory distress (tachypnea, grunting, retractions, cyanosis) with onset within 6 hours after birth and persistence for at least 12 hours.
2. Chest X- ray findings that indicate at least one of the following: prominent central vascular markings, widened interlobar fissures of pleural fluid, symmetrical perihilar congestion, hyperaeration as evidenced by flattening and depression of the diaphragmatic domes or increased antero-posterior diameter or both.

3. Exclusion of any competing diagnosis such as surfactant deficiency, pneumonia, meconium aspiration, congenital heart disease or metabolic disorder, to explain respiratory distress.

Infants with respiratory symptoms due to transitional delay, pneumonia, respiratory distress syndrome, air leak syndromes, congenital heart disease, meconium aspiration, metabolic disorders (such as hypoglycemia, polycythemia), asphyxia (umbilical artery $\mathrm{pH}<$ 7.10 and/or $\mathrm{HCO}_{3}{ }^{-}>12, \mathrm{BE}>-10$, APGAR score at $5 \mathrm{~min}<3$ ) and congenital lung anomalies were excluded from the study group. Exclusion of respiratory and non-respiratory disorders likely to cause respiratory symptoms were made by radiological and laboratory findings.

Newborns having the diagnosis of TTN were classified into two groups according to the intensity of the respiratory support. Infants receiving only supplemental oxygen and infants requiring nasal continuous positive airway pressure (CPAP) or mechanical ventilation constituted group 1 (mild) and group 2

Table I. Demographic and Clinical Findings of the Patients with Transient Tachypnea of the Neonate $(n=35)$

\begin{tabular}{lc}
\hline Gestational age (weeks) (mean \pm SD) & $37.1 \pm 1.6(34-40)$ \\
Birth weight $(\mathrm{g})$ (mean $\pm \mathrm{SD}$ ) & $3047 \pm 701$ \\
Gender (male/female) & $23 / 12$ \\
Type of birth (CS/NVD) & $31 / 4$ \\
5 min APGAR score, median (min-max) & $9(5-10)$ \\
Respiratory rate on admission, median (min-max) & $69(52-90)$ \\
Peak respiratory rate in first 24 hr, median (min-max) & $72(60-90)$ \\
Peak respiratory rate in 24-48 hr, median (min-max) & $58(42-76)$ \\
Silverman score, median (min-max) & $5(2-10)$ \\
Richardson score, median (min-max) & $2(0-7)$ \\
Duration of oxygen support (hours), median (min-max) & $30(12-221)$ \\
Respiratory support & \\
Treatment Oxygen (n, \%) & $15(43 \%)$ \\
CPAP (n, \%) & $18(52 \%)$ \\
Mechanical ventilation (n,\%) & $2(5 \%)$ \\
Duration of hospitalization (days) (mean \pm SD) & $4.3 \pm 2.9$ \\
\hline
\end{tabular}

CS: cesarean section, NVD: normal vaginal delivery, CPAP: continuous positive airway pressure 
Table II. Comparison of Clinical Characteristics in Two Groups.

\begin{tabular}{lccc}
\hline & $\begin{array}{c}\text { Group 1(oxygen/ } \\
\text { mild) } \mathrm{n}=15\end{array}$ & $\begin{array}{c}\text { Group 2 } \\
(\mathrm{CPAP} \text { or MV/severe) } \\
\mathrm{n}=20\end{array}$ & $\mathrm{p}$ \\
\hline Gestational age (weeks) (mean $\pm \mathrm{SD})$ & $37.7 \pm 1.6$ & $36.6 \pm 1.5$ & $0,048^{*}$ \\
Birth weight (g) (mean $\pm \mathrm{SD})$ & $3272 \pm 605$ & $2878 \pm 735$ & 0.1 \\
Gender (male/female) (\%) & $73.3 / 26.7$ & $60 / 40$ & 0.41 \\
Type of birth (CS/NVD) (\%) & $86.7 / 13.3$ & $90 / 10$ & 1 \\
APGAR score at 5 min, median (min-max) & $9(7-9)$ & $9(5-10)$ & 0.47 \\
Respiratory rate on admission, (mean $\pm \mathrm{SD})$ & $72.3 \pm 6.9$ & $67 \pm 9.5$ & 0.12 \\
Peak respiratory rate in first 24 hr (mean $\pm \mathrm{SD})$ & $74.2 \pm 6.9$ & $71 \pm 7.8$ & 0.22 \\
Peak respiratory rate in 24-48 hr (mean $\pm \mathrm{SD})$ & $56.5 \pm 6.7$ & $60 \pm 7.3$ & 0.17 \\
Silverman score (median) & $4(2-8)$ & $6(4-10)$ & $<0,01^{*}$ \\
Richardson score (median) & $2(0-5)$ & $4(0-7)$ & $<0,01^{*}$ \\
Mean duration oxygen support (hour) & $24.7 \pm 12.1$ & $72.1 \pm 61.1$ & $0.006^{*}$ \\
Mean duration of hospitalization (days) & $2.4 \pm 1.1$ & $5.7 \pm 3.1$ & $0,001^{*}$ \\
(mean \pm SD) & & & \\
\hline
\end{tabular}

* $\mathrm{p}$ value $<0.05$ was regarded as statistically significant

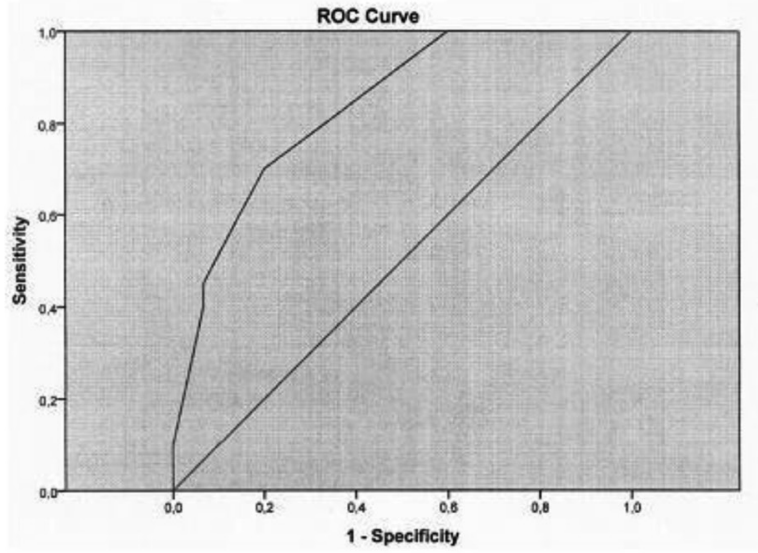

Silverman Score

Fig. 1. ROC Curves of Silverman and Richardson Scores

(severe), respectively. Demographic, clinical and laboratory characteristics were compared between two groups.

Indications for CPAP treatment were:

1. SatO 2 below $90 \%$ with free flow $\mathrm{FiO}_{2} \geq 60 \%$

2. $\mathrm{PaCO}_{2}>50 \mathrm{mmHg}$ and /or $\mathrm{PaO}_{2}<50$ mmHg with free flow $\mathrm{FiO}_{2} \geq 60 \%$

Indication for mechanical ventilation treatment were:

1. Presence of severe to moderate respiratory distress under CPAP treatment

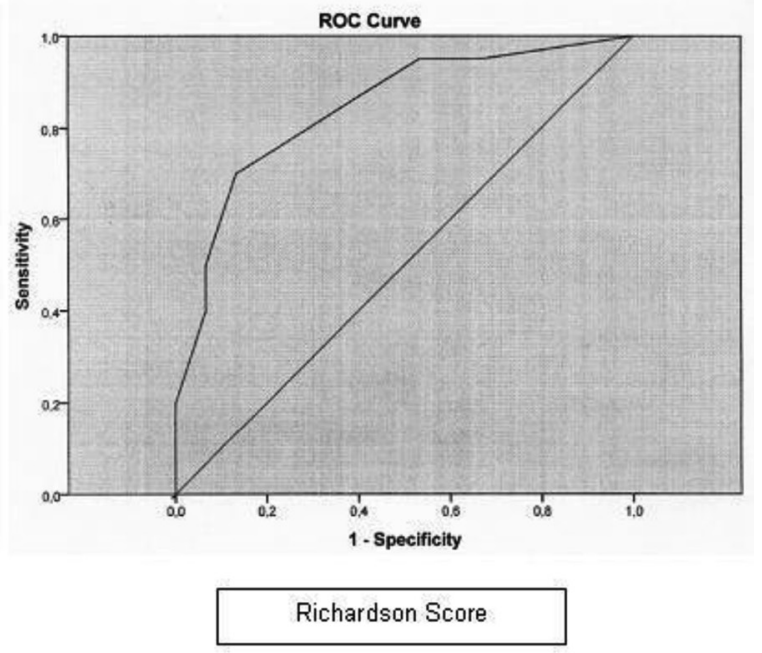

2. Sat $\mathrm{O} 2<90 \%$ on $8 \mathrm{~cm} \mathrm{H}_{2} \mathrm{O}$ nCPAP at $\mathrm{FiO}_{2}>60 \%$

3. $\mathrm{PaCO}_{2}>50 \mathrm{mmHg}$ and /or $\mathrm{PaO}_{2}<50$ $\mathrm{mmHg}$ on $8 \mathrm{~cm} \mathrm{H} \mathrm{H}_{2} \mathrm{O}$ nCPAP at $\mathrm{FiO}_{2}>60 \%$

4. Hemodynamic instability (Mean blood pressure $<35 \mathrm{~mm} \mathrm{Hg}$, capillary refill $>3 \mathrm{sec}$ )

5. Apneic and/or hypoxic episodes under NCPAP

Nasal CPAP was provided by a neonatal CPAP device (Viasys Healthcare, Infant Flow NCPAP System, UK) with short binasal prongs and invasive mechanical ventilation was provided 


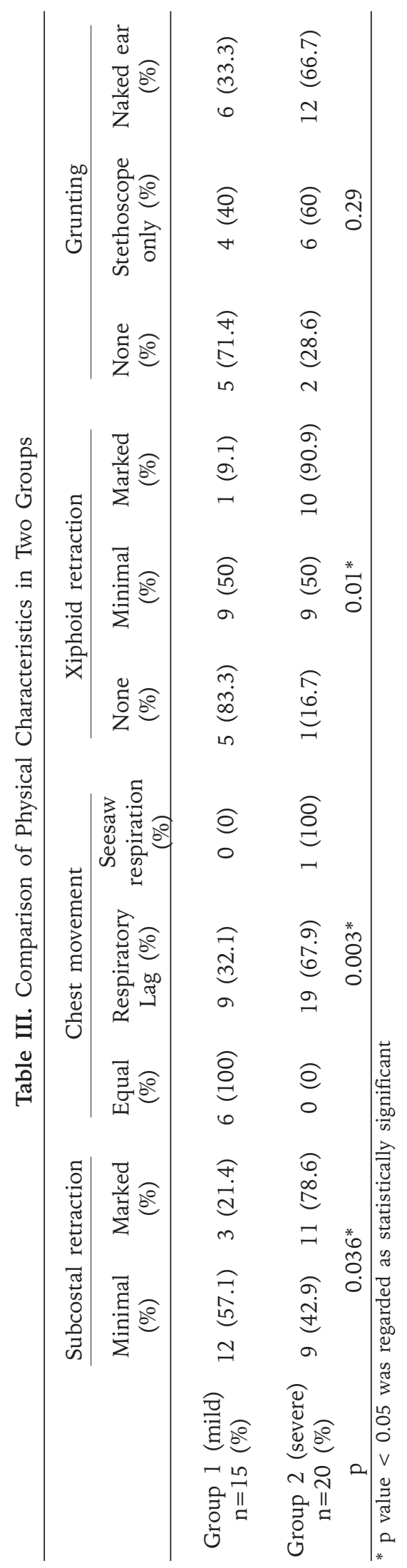

by a mechanical ventilator (Stephan, Sophie Neonatology Ventilator, Germany) in volume targeted mode. Initial NCPAP parameters were $5 \mathrm{~cm}-\mathrm{H}_{2} \mathrm{O}$ PEEP and $40 \% \mathrm{FiO}_{2}$.

The initial ventilator parameters were adjusted as to achieve a $5 \mathrm{ml} / \mathrm{kg}$ tidal volume, $40 \% \mathrm{FiO}_{2}$, $5 \mathrm{~cm}-\mathrm{H}_{2} \mathrm{O}$ PEEP and ventilator settings were adjusted according to the blood gas parameters.

\section{Statistical analysis}

Statistical analysis was done using SPSS version 16.0 (SPSS, Chicago, IL, USA). To compare the proportions among the groups, either $\chi^{2}$ test or Fisher's exact test was used; to compare the means among the groups the t-test or the Mann-Whitney U-test was used depending on the sample size. $\mathrm{P}$ value $<0.05$ was regarded as statistically significant. Receiver operating characteristic curve was used to determine the cut-off for Silverman and Richardson scores. Parameters were compared between the groups and statistical significance was assessed by logistic regression to determine the independent predictive value of a specific parameter.

\section{Results}

During the study period, 300 newborns $\geq$ 34 weeks gestation admitted to our NICU. Sixty of these infants had respiratory distress symptoms. Among these 60 infants, 35 infants were diagnosed as TTN, 12 infants as neonatal pneumonia, 11 infants as delay of transition, 1 infant as respiratory distress syndrome and 1 infant as pneumothorax. Demographic and clinical findings of the patients with TTN are presented in Table I.

Comparison of clinical characteristics of both groups demonstrated that patients in group 2 had lower gestational age, higher Silverman and Richardson scores, longer mean duration of oxygen support and hospitalization (Table II). The cut-off for the Silverman score to predict the need of non-invasive or invasive ventilation was 6 with $70 \%$ sensitivity and $80 \%$ specificity and the cut off for Richardson score was 3 with $70 \%$ sensitivity and $86 \%$ specificity (Fig. I). A positive correlation was found between subcostal and xiphoid retractions on the first physical examination after admission, asynchrony in chest-abdomen movements, arterial $\mathrm{pH}<7.30$, ratio of $\mathrm{PaO}_{2} / \%$ inspired 
Table IV. Comparison of Laboratory Characteristics in Two Groups

\begin{tabular}{|c|c|c|c|c|c|c|c|}
\hline & \multicolumn{4}{|c|}{ Arterial pH-pCO2 } & \multicolumn{3}{|c|}{ Arterial $\mathrm{pO} 2 / \mathrm{FiO} 2$} \\
\hline & $\begin{array}{c}\mathrm{pH}>7.30 \\
(\%)\end{array}$ & $\begin{array}{c}\mathrm{pH} \text { 7.25-7.29, } \\
\text { p CO2<50 } \\
(\%)\end{array}$ & $\begin{array}{c}\mathrm{pH} \text { 7.25-7.29, } \\
\mathrm{p} \mathrm{CO}>50 \\
(\%)\end{array}$ & $\begin{array}{c}\mathrm{pH}<7.25 \\
(\%)\end{array}$ & $\begin{array}{l}>2.5 \\
(\%)\end{array}$ & $\begin{array}{l}1.2-2.4 \\
(\%)\end{array}$ & $\begin{array}{l}<1.2 \\
(\%)\end{array}$ \\
\hline $\begin{array}{l}\text { Group } 1 \text { (mild) } \\
\mathrm{n}=15(\%)\end{array}$ & $\begin{array}{c}12 \\
(57.1)\end{array}$ & $\begin{array}{c}3 \\
(21.4)\end{array}$ & $\begin{array}{c}6 \\
(100)\end{array}$ & $\begin{array}{c}9 \\
(32.1)\end{array}$ & $\begin{array}{c}8 \\
(80)\end{array}$ & $\begin{array}{c}7 \\
(43.8)\end{array}$ & $\begin{array}{c}0 \\
(0)\end{array}$ \\
\hline $\begin{array}{l}\text { Group } 2 \text { (severe) } \\
\mathrm{n}=20(\%)\end{array}$ & $\begin{array}{c}9 \\
(42.9)\end{array}$ & $\begin{array}{c}11 \\
(78.6)\end{array}$ & $\begin{array}{c}0 \\
(0)\end{array}$ & $\begin{array}{c}19 \\
(67.9)\end{array}$ & $\begin{array}{c}2 \\
(20)\end{array}$ & $\begin{array}{c}9 \\
(56.2)\end{array}$ & $\begin{array}{c}9 \\
(100)\end{array}$ \\
\hline $\mathrm{p}$ & \multicolumn{4}{|c|}{$0.036^{*}$} & \multicolumn{3}{|c|}{$0.02 *$} \\
\hline
\end{tabular}

$* \mathrm{p}$ value $<0.05$ was regarded as statistically significant

$\mathrm{O}_{2}<1.2$ and need of respiratory support $(\mathrm{p}<$ 0.05) (Table III-IV).

In addition, assessment of the aforementioned significantly different parameters on logistic regression demonstrated that xiphoid retractions independently had an odds ratio of 12.6 (95\% C.I 1.06-150.71) for assessing further need for respiratory support.

\section{Discussion}

This prospective cohort study demonstrated that higher Silverman and Richardson scores were predictive for further respiratory support in patients with the diagnosis of TTN, and positive correlations were found between subcostal and xiphoid retractions on the first physical examination after admission, asynchrony in chest-abdomen movements, arterial $\mathrm{pH}<7.30$, ratio of $\mathrm{PaO}_{2} / \%$ inspired $\mathrm{O}_{2}<1.2$ and further need for invasive and noninvasive respiratory support.

TTN is usually a benign and self-limited disease. However, associated hypoxemia and respiratory failure increase the need of ventilation support and the number of NICU admissions. More than half of our patients $(57 \%)$ required respiratory support. In the study of Kasap et al. ${ }^{6}, 47(49.4 \%)$ out of 95 TTN patients needed respiratory support. In another study by Weintraub et al. ${ }^{15}$, out of 745 neonates with the initial diagnosis of TTN, 336 (45\%) infants required CPAP or high flow nasal canula treatment.

Evidence-based approaches for interpreting physiologic data in neonates $\geq 34$ week gestation presenting with respiratory distress including the diagnosis of TTN are not widely used. However, Escobar et al. ${ }^{13}$ developed a model to predict death and the need of prolonged assisted ventilation in newborns $\geq 34$ weeks with respiratory distress. In his study, 203 (9.3\%) infants needed assisted ventilation longer than 3 days or died among 2276 newborns. A simple score based on gestational age, the lowest $\mathrm{PaO}_{2} / \mathrm{FiO}_{2}$ and the lowest mean arterial blood pressure had a predictive value with a 0.80 validation data set. On the other hand Richardson and Silverman scores were used to determine the severity of respiratory distress of the newborns in few studies ${ }^{12-14,16}$. Silverman scores above 6 and Richardson scores above 3 are usually accepted as to be related to severe respiratory distress ${ }^{13,14,16}$. Our results confirm these findings.

Contrary to the study by Kasap et al. ${ }^{6}$ which demonstrated that respiratory rate peak during 36 hours $>90 / \mathrm{min}$ caused a 7.04 -fold risk of prolonged tachypnea, peak respiratory rates at 24 and 48 hours were not different between groups in our study. However, we demonstrated significant difference in Silverman and Richardson scores between the groups. We suggest that subcostal and xiphoid retractions and arterial $\mathrm{pH}$ and arterial $\mathrm{PaO}_{2} / \%$ inspired $\mathrm{O}_{2}$ ratio on admission are significant predictors of subsequent respiratory support. Oztekin et al. ${ }^{17}$ assessed respiratory rates and blood gases in the first postnatal hour to predict the duration of respiratory support in patients with TTN. Respiratory rates were not different between their groups but $\mathrm{pH}<7.22$ had a $97.7 \%$ sensitivity to predict the need of respiratory support for $>5$ days $^{17}$. Arterial $\mathrm{pH}<7.30$ and ratio of arterial $\mathrm{PaO}_{2} / \%$ inspired $\mathrm{O}_{2}<1.2$ were found to be significant in the group who need invasive and non-invasive respiratory support in our study. 
Certain limitations to our analysis must be stressed. First it is a single center study with a limited number of cases. Second, we did not present any data related to maternal complications that may be associated with TTN.

In conclusion, we think that simple scores can help nurses and physicians to get a good sense of a given baby's likelihood of deterioration. Subcostal and xiphoid retractions on the first physical examination, asynchrony in chestabdomen movements, arterial $\mathrm{pH}<7.30$ and ratio of $\mathrm{PaO}_{2} / \%$ inspired $\mathrm{O}_{2}<1.2$ may be helpful for clinicians in decision making for referral of the patients to a secondary or a tertiary level NICU. Despite its limitations, this study can serve as a useful adjunct to clinical evaluation of neonates with the diagnosis of TTN and we hope that it will encourage the use of physiologic data in decision making.

\section{REFERENCES}

1. Riskin A, Abend-Weinger M, Riskin-Mashiah S, Kugelman A, Bader D. Cesarean section, gestational age, and transient tachypnea of the newborn: timing is the key. Am J Perinatol 2005; 22: 377-382.

2. Altman $M$, Vanpee $M$, Cnattingius S, Norman $M$. The Risk Factors For Acute Respiratory Morbidity In Moderatly Preterm Infants, Pediatric and Perinatal Epidemiology 2013; 27: 172-181.

3. Consortium On Safe Labor, Hibbard JU, Wilkins I, Sun L, et al. Respiratory morbidity in late preterm births. JAMA 2010; 304: 419-425.

4. Yurdakök M. Transient tachypnea of the newborn: what is new?. J Matern Fetal Neonatal Med 2010; 23: 24-26.

5. Atasay B, Ergun H, Okulu E, Mungan Akın I, Arsan S. The Association Between Cord Hormones And Transient Tachypnea Of Newborn in Late Preterm and Term Neonates Who Were Delivered by Cesarean Section. J Matern Fetal Neonatal Med 2013; 26: 877880.

6. Kasap B, Duman N, Ozer E, Tatli M, Kumral A, Ozkan $\mathrm{H}$. Transient tachypnea of the newborn: predictive factor for prolonged tachypnea. Pediatr Int 2008; 50 : 81-84.
7. Ozkiraz S, Gokmen Z, Boke SB, Kilicdag H, Ozel D, Sert A. Lactate and lactate dehydrogenase in predicting the severity of transient tachypnea of the newborn. J Matern Fetal Neonatal Med 2013; 26: 1245-1248.

8. Takaya A, Igarashi M, Nakajima M, Miyake H, Shima Y, Suzuki S. Risk factors for transient tachypnea of the newborn in infants delivered vaginally at 37 weeks or later. J Nippon Med Sch 2008; 75: 269-273

9. Costa S, Rocha G, Letio A, Guimaraes H. Transient tachypnea of the newborn and congenital pneumonia: a comparative study. J Matern Fetal Neonat Med 2012; 25: 992-994

10. Derbent A, Tatli M, Duran M, et al. Transient tachypnea of the newborn: effects of labor and delivery type in term and preterm pregnancies. Arch Gynecol Obstet 2011; 283: 947-951

11. Bak SY, Shin YH, Jeon JH, et al. Prognostic factors for treatment outcomes in transient tachypnea of the newborn. Pediatr Int 2012; 54: 875-880

12. Dumas de la Roque E, Bertrand C, Tandonnet O, et al. Nasal high frequency percssive ventilation versus nasal continuous positive airway pressure in transient tachypnea of the newborn: a pilot randomized controlled trial (NCT00556738). Pediatric Pulmonol 2011; 46: 218-223

13. Escobar G, Shaheen S, Breed E, et al. Richardson score predicts short term adverse respiratory outcomes. J Pediatr 2004; 145: 754-760

14. Silverman WC, Anderson DH. Controlled Clinical trial on effects of water mist on obstructive respiratory signs, death rate and necropsy findings among premature infants. Pediatrics 1956; 17: 1-10

15. Weintraub AS, Cadet CT, Perez R, DeLorenzo E, Holzman IR, Stroustrup A. Antibiotic use in newborns with transient tachypnea of the newborn. Neonatology. 2013; 103: 235-240

16. Mathai S, Raju C, Kanitkar CM. Management of respiratory distress in the newborn. MJAFI 2007; 63: 269-272

17. Oztekin O, Kalay S, Tezel G, Akcakus M, Oygur N. Can we predict the duration of respiratory support in transient tachypnea of the newborn?. Turk J Med Sci 2012; 42: (Suppl.2): 1494-1498. 